\title{
Multivariate Quadratic Nonlinear Regression Model of the Ultimate Pull-Out Load of Electrohydraulic Expansion Joints Based on Response Surface Methodology
}

\author{
Da Cai, Chenyu Jin, Jie Liang, Guangyao Li and Junjia Cui * (i)
}

check for updates

Citation: Cai, D.; Jin, C.; Liang, J.; Li,

G.; Cui, J. Multivariate Quadratic

Nonlinear Regression Model of the

Ultimate Pull-Out Load of

Electrohydraulic Expansion Joints

Based on Response Surface

Methodology. Coatings 2021, 11, 689.

https://doi.org/10.3390/

coatings11060689

Academic Editor: Yong X. Gan

Received: 1 May 2021

Accepted: 5 June 2021

Published: 9 June 2021

Publisher's Note: MDPI stays neutra with regard to jurisdictional claims in published maps and institutional affiliations.

Copyright: (c) 2021 by the authors. Licensee MDPI, Basel, Switzerland. This article is an open access article distributed under the terms and conditions of the Creative Commons Attribution (CC BY) license (https:// creativecommons.org/licenses/by/ $4.0 /)$
State Key Laboratory of Advanced Design and Manufacturing for Vehicle Body, Hunan University, Changsha 410082, China; caida@hnu.edu.cn (D.C.); jcydawn1996@hnu.edu.cn (C.J.); jieliang@hnu.edu.cn (J.L.); gyli@hnu.edu.cn (G.L.)

* Correspondence: cuijunjia@hnu.edu.cn; Tel.: +86-731-88821445; Fax: +86-731-88822051
Abstract: Electrohydraulic expansion joining has great potential for joining the light weight and high strength thin-walled pipes due to its high strain rate. Based on the central composite design (CCD) of response surface methodology, multiple experiments of electrohydraulic expansion joining process were performed. The multivariate quadratic nonlinear regression model between process parameters (discharge voltage, wire length, and wire diameter) and the ultimate pull-out load of the joints was established. The results revealed that discharge voltage, wire length and wire diameter all had a significant effect on the ultimate pull-out load. The discharge voltage had the most significant effect. The interaction between the discharge voltage and the wire diameter had a significant effect on the ultimate pull-out load. The optimal parameter combination (discharge voltage $=6 \mathrm{kV}$, wire length $=$ $10 \mathrm{~mm}$, wire diameter $=0.833 \mathrm{~mm}$ ) was obtained and verified through the experiments. This study would provide guidance for the choice of the process parameters in real applications.

Keywords: electrohydraulic expansion joining; aluminum alloy pipe; ultimate pull-out load; response surface methodology

\section{Introduction}

In recent years, the weight reduction of vehicles has become the focus of the development of the automotive and aviation manufacturing industries [1-3]. Successful approaches to reduce weight included the optimal design of structures and the use of lightweight materials [4-6]. However, the potential for weight reduction using pipe joining parts and frame structures made from lightweight materials was limited by the conventional joining technology [7]. The conventional joining technologies included: thermal welding, mechanical fastening, and adhesive bonding. However, 6000 series aluminum alloy, which was suitable for pipe joining parts and frame structures, was easy to crack during thermal welding [8]. Mechanical fastening easily caused uneven stress distribution. Adhesive bonding required high surface quality. The joining by forming processes could overcome certain disadvantages.

The joining by forming processes was a technology that join two or more workpieces by plastically deforming at least one part or additional fastener [9]. The advantages of joining by forming processes are a wide range of materials, including dissimilar materials (metal/non-metal), less embrittlement and tensile residual stress, high process reliability, and environmental safety [9]. The joining by forming processes can be classified based on forming direction, forming energy and strain rate. The forming direction was divided into expansion and compression. According to the forming energy transfer mode, the joining was divided into mechanical tool contact, liquid medium, and working energy transfer energy. Based on the strain rate, the joining was divided into joining by quasi-static forming and joining by high-speed forming. 
The joining by quasi-static forming processes includes joining by rolling, joining by hydroforming, mechanical crimping, hydraulic crimping, and joining by impulse forming. For the joining by rolling, Henriksen et al. used numerical simulation and experiment methods to study the joining of steel pipes and steel flanges [10]. In the study of joining by hydroforming, Marre et al. explored the influence of different groove design on the axial and torque load through experiments [11]. In the mechanical crimping process of steel pipe, the pull-out strength was affected by the positioning of the workpiece and the movement of the indenter [12]. The interference pressure between the joining parts was considered to be a direct cause of the pull-out strength [13]. Hydraulic crimping used elastic media to apply forming pressure. Friction coefficient and yield stress were the main factors affecting the quality of hydraulic crimping [14]. However, the low formability of lightweight high strength alloys at room temperature could cause cracking problems [15].

Different from joining by quasi-static forming, joining by impulse forming is a highspeed joining technology that can improve formability [16]. Electromagnetic forming and electrohydraulic forming are typical pulse forming, which can be used to manufacture joints of various materials. Weddeling et al. established an analysis method for determining process parameters such as discharge energy based on groove geometry and workpiece characteristics in electromagnetic crimping process [4]. During the electro-magnetic crimping joining process, the discharge energy and the groove characteristics would affect the strength of the joint. In response to this characteristic, Weddeling et al. established an analysis method for determining process parameters such as discharge energy based on groove geometry and workpiece characteristics in the joining process $[4,17]$. The pipes could also be joined by electrohydraulic expansion joining [18]. Compared with joining by quasi-static forming processes, the electrohydraulic expansion joining improves the forming limit of the forming area and joining efficiency. Compared with joining by electromagnetic forming, a more uniform pressure distribution can be obtained during the presented process $[19,20]$. Different discharge energy will affect the pull-out load and the failure mode of the joints. In the electrohydraulic forming process, in addition to the discharge energy, the diameter and length of the wire can also affect the forming result [21]. Therefore, the discharge energy and the wire characteristics (diameter and length) have a great influence on the electrohydraulic expansion joining. However, the influence of these parameters on the pull-out load of the joints and the corresponding mathematical relationships have not been reported.

In this paper, the experimental design method and mathematical statistical analysis method were applied to investigate the influence of discharge energy, wire length and wire diameter on the pull-out load of electrohydraulic expansion joints. Aluminum alloy pipes and stainless-steel pipes were selected as test materials. Firstly, the experiment was designed based on the central composite design (CCD) technology. Secondly, the experimental results were statistically analyzed to obtain the multivariate nonlinear regression model of the ultimate pull-out load of electrohydraulic expansion joints based on response surface methodology. Subsequently, the model was used to analyze the influence of each parameter on the pull-out load separately and interactively. The main factors that affect the pull-out load were found. Finally, the process parameters were optimized with the goal of the ultimate pull-out load. Experiments were carried out to verify the optimization results under the optimized settings.

\section{Materials and Methods}

\subsection{Electrohydraulic Expansion Joining}

The electrohydraulic expansion joining process was used to obtain joints. Figure 1a shows the joining equipment. The equipment mainly included magnetic pulse generator and joining device. The magnetic pulse generator provided joining energy. The joining device was composed of joining die, two electrodes, and wire. The generator had 6 capacitors (maximum capacitance $408 \mu \mathrm{F}$ ) and a maximum discharge voltage of $16 \mathrm{kV}$. 


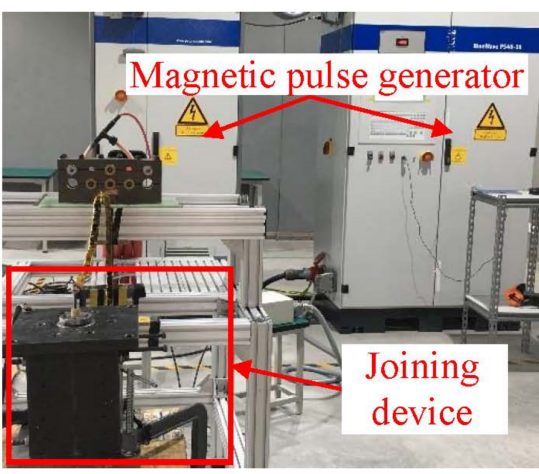

(a)

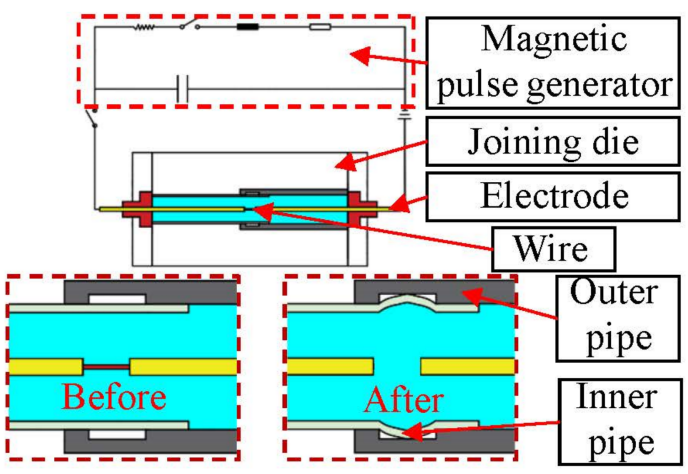

(b)

Figure 1. Principal of electrohydraulic expansion joining: (a) joining equipment; (b) joining diagram and process.

During the joining process, the energy stored in the capacitor was instantly released on the wire between the electrodes. A high-pressure plasma channel was formed. The shock waves caused by the expansion of the plasma channel were transmitted to the inner pipe at high speeds. The material of the inner pipe was formed into the groove of the outer pipe by the mass and momentum of the water in the shock wave. As shown in Figure $1 \mathrm{~b}$, an interlocking joint that could transmit loads was formed. The wire material was aluminum. For the convenience of operation and in order to ensure the quality of the joining, the length of the wire was set to $10 \mathrm{~mm}, 15 \mathrm{~mm}$, and $20 \mathrm{~mm}$. Wire diameter was set to $0.6 \mathrm{~mm}, 0.8 \mathrm{~mm}$, and $1 \mathrm{~mm}$. The discharge voltages of $4 \mathrm{kV}, 5 \mathrm{kV}$, and $6 \mathrm{kV}$ were selected.

\subsection{Materials and Specimen Preparation}

In this paper, 6063 aluminum alloy inner pipe and 304 stainless steel outer pipe were joined by electrohydraulic expansion joining. Figure 2 shows the geometric dimensions of the specimens. The length of the inner pipe was the same as that of the outer pipe, which was $110 \mathrm{~mm}$. The inner diameter of the outer pipe was $25 \mathrm{~mm}$. The outer diameter of the outer pipe was $30 \mathrm{~mm}$. The inner pipe had an inner diameter of $23 \mathrm{~mm}$ and an outer diameter of $25 \mathrm{~mm}$. The inner pipe and the outer pipe overlapped at the end. The total length of the joint was $200 \mathrm{~mm}$. The length of the overlap area was $20 \mathrm{~mm}$. The rectangular groove was machined inside the outer pipe along the circumferential direction. The depth of the rectangular groove was $1 \mathrm{~mm}$, and the width was $6 \mathrm{~mm}$.

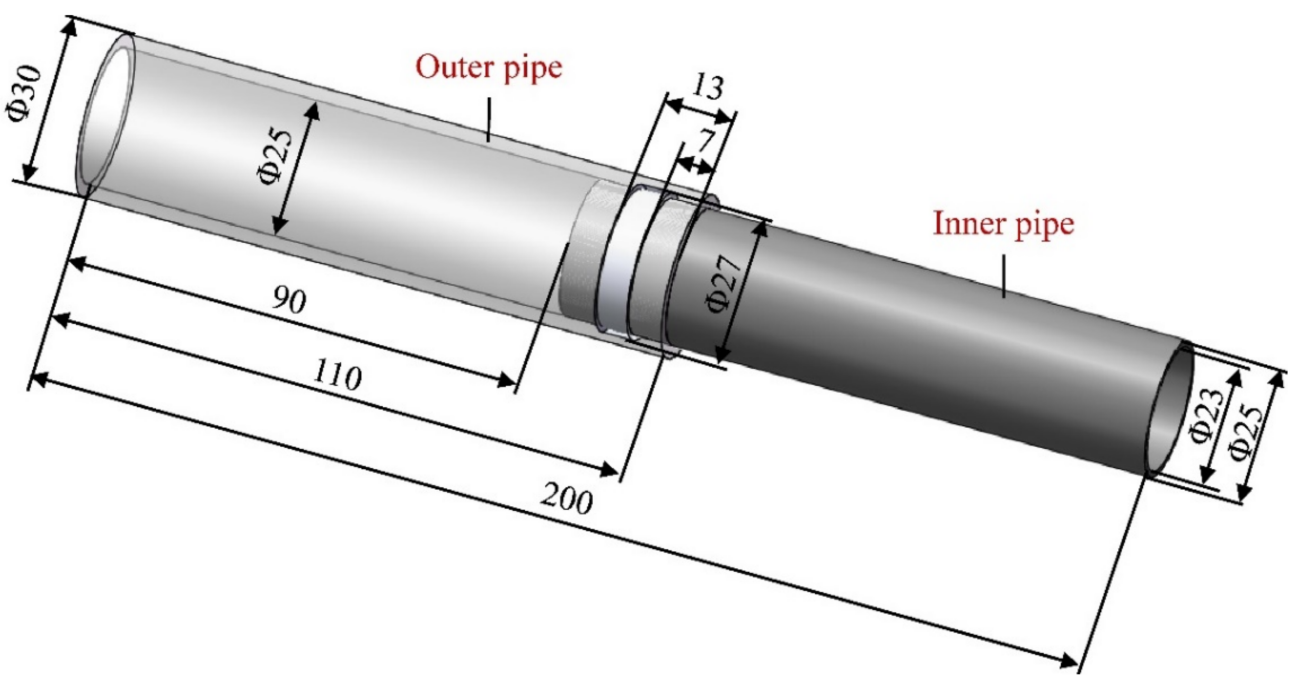

Figure 2. Diagram of the joining specimens (Unit: $\mathrm{mm}$ ). 


\subsection{Joint Quality Evaluation}

The mechanical properties of the joints were evaluated through pull-out tests. The pull-out tests were carried out on the INSTRON 5985 universal testing machine. Two different V-shaped fixtures were designed according to the outer diameter of the inner and outer pipes. The steel mandrels were inserted at both ends of the joints to ensure that the pipes would not deform in the radial direction during the clamping process. The deformation of the pipes in the radial direction would affect the test results. The loading speed was set to $2 \mathrm{~mm} / \mathrm{min}[22,23]$. For each combination of parameters, three repeated experiments were performed.

\subsection{Experiment Design}

CCD is a mathematical method suitable for multi-factor testing. It is well adapted to analysis of the relationship among variables. The method is divided into two subsets. One subset estimates the liner relationship and interaction between the variables. The other subset determines the relative importance of each variable relative to the estimated response. This method also contains a lot of information about variables and experiment error $[24,25]$. Three independent variables (discharge voltage, wire length, and wire diameter) were investigated in this study. The corresponding numbers of the three variables were $A, B$, and $C$, respectively. The correspondence table of actual and coded values was shown in Table 1. In Table 1, "0" represented the center level, " -1 " represented low level, and " 1 " represented high level. The experimental design data based on CCD was shown in Table 2. All samples were obtained in triplicate.

Table 1. Correspondence table of actual and coded values.

\begin{tabular}{ccccc}
\hline \multirow{2}{*}{ Variable } & \multirow{2}{*}{ Numbering } & \multicolumn{3}{c}{ Coded Values } \\
\cline { 3 - 5 } & & $\mathbf{- 1}$ & $\mathbf{0}$ & $\mathbf{1}$ \\
\hline Discharge voltage & $\mathrm{A}$ & 4 & 5 & 6 \\
Wire length & $\mathrm{B}$ & 10 & 15 & 20 \\
Wire diameter & $\mathrm{C}$ & 0.6 & 0.8 & 1.0 \\
\hline
\end{tabular}

Table 2. Central composite design.

\begin{tabular}{|c|c|c|c|c|c|c|}
\hline \multirow{2}{*}{ Samples } & \multicolumn{3}{|c|}{ Coded Value } & \multicolumn{3}{|c|}{ Real Value } \\
\hline & A & B & $\mathrm{C}$ & Discharge Voltage (kV) & Wire Length (mm) & Wire Diameter (mm) \\
\hline 1 & -1 & -1 & -1 & 4 & 10 & 0.6 \\
\hline 2 & 0 & -1 & 0 & 5 & 10 & 0.8 \\
\hline 3 & 0 & 0 & -1 & 5 & 15 & 0.6 \\
\hline 4 & -1 & 0 & 0 & 4 & 15 & 0.8 \\
\hline 5 & 0 & 0 & 1 & 5 & 15 & 1.0 \\
\hline 6 & 1 & 1 & -1 & 6 & 20 & 0.6 \\
\hline 7 & 0 & 0 & 0 & 5 & 15 & 0.8 \\
\hline 8 & -1 & 1 & 1 & 4 & 20 & 1 \\
\hline 9 & -1 & -1 & 1 & 4 & 10 & 1 \\
\hline 10 & 0 & 1 & 0 & 5 & 20 & 0.8 \\
\hline 11 & 1 & 1 & 1 & 6 & 20 & 1 \\
\hline 12 & 0 & 0 & 0 & 5 & 15 & 0.8 \\
\hline 13 & 0 & 0 & 0 & 5 & 15 & 0.8 \\
\hline 14 & 0 & 0 & 0 & 5 & 15 & 0.8 \\
\hline 15 & 1 & -1 & -1 & 6 & 10 & 0.6 \\
\hline 16 & -1 & 1 & -1 & 4 & 20 & 0.6 \\
\hline 17 & 1 & 0 & 0 & 6 & 15 & 0.8 \\
\hline 18 & 1 & -1 & 1 & 6 & 10 & 1 \\
\hline 19 & 0 & 0 & 0 & 5 & 15 & 0.8 \\
\hline 20 & 0 & 0 & 0 & 5 & 15 & 0.8 \\
\hline
\end{tabular}




\subsection{Data Analysis}

The response surface method is an efficient mathematical and statistical technique that can be used to analyze the effects of different independent variables on the response of the complex system. This method can be used to optimize the response based on the rages of variables. The optimal set of variables can be obtained [26]. The relationship between the response and variables in the surface model can be established. The mathematical function between the response and variables can be determined. In this study, the functional relationships between response (ultimate pull-out load) and factors (discharge voltage, wire length and wire diameter) were obtained by the following second-order polynomial regression model:

$$
y=\beta_{0}+\sum_{i=1}^{k} \beta_{i} x_{i}+\sum_{i=1}^{k} \beta_{i i} x_{i}^{2}+\sum_{i} \sum_{j} \beta_{i j} x_{i} x_{j}
$$

where, $\beta_{0}$ is regression intercept. $\beta_{i}, \beta_{i i}, \beta_{i j}$ are the linear, quadratic, and linear interaction effects of the factors, respectively. $x_{i}, x_{j}$ are the selected factors in the electrohydraulic expansion joining process, $y$ refers to the response that is the ultimate pull-out load. The analysis of variance and range analysis were used to analyze the test data. The response surface method was implemented based on CCD using the Design Expert Software.

\section{Results and Discussion}

\subsection{Mechanical Properties of the Joints}

The electrohydraulic expansion joints in the CCD are shown in Figure 3. Initially, the inner pipes were observed to be plastically deformed at the grooves of the outer pipes. The inner pipes and the outer pipes were connected together to form the joints.

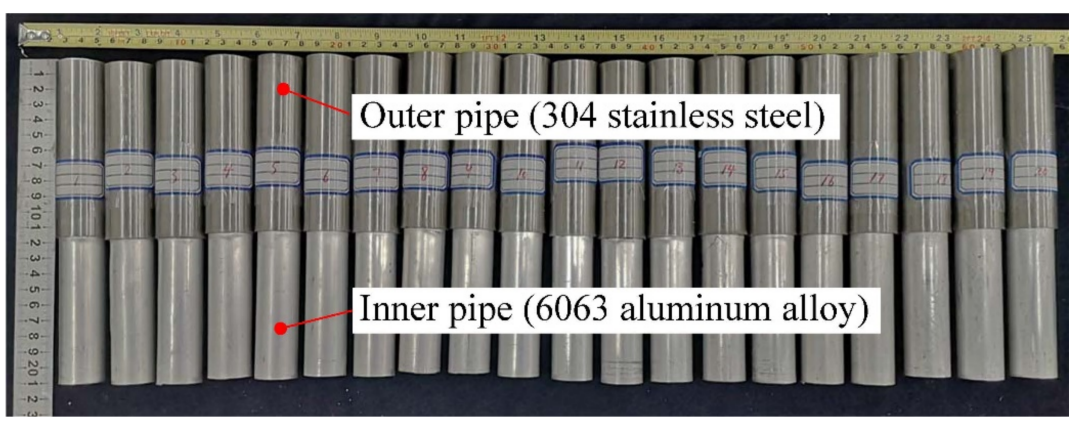

Figure 3. Electrohydraulic expansion joints in the CCD.

As shown in Figure 4, pull-out tests were carried out to obtain the response parameter (ultimate pull-out load). The ultimate pull-out load was to evaluate the mechanical properties of the joints. During the test, two mandrels were placed at the inner end of the pipes. The mandrels had sufficient length to ensure that the joints could be clamped and not deformed in the radial direction.

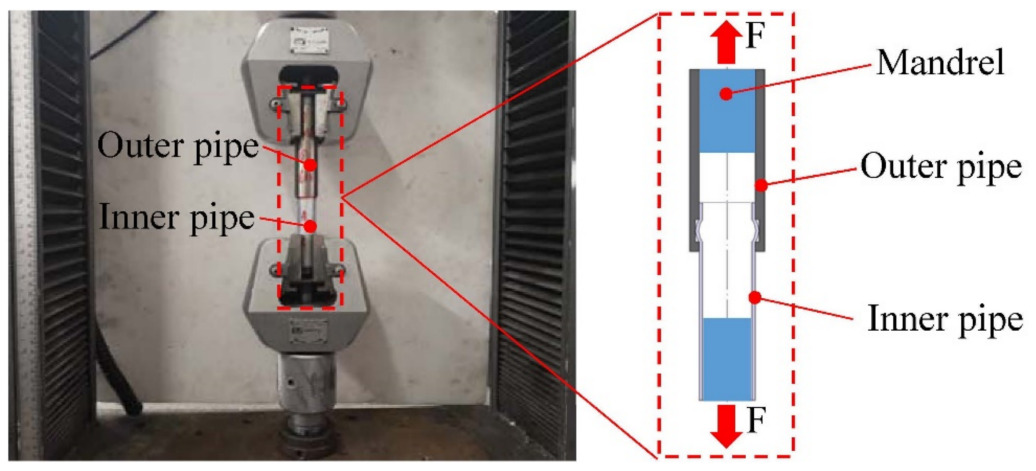

Figure 4. Pull-out tests and clamping method. 
The ultimate pull-out loads obtained based on the CCD are shown in Table 3. In the pull-out test results, the lowest ultimate pull-out load was $2.17 \mathrm{kN}$, the corresponding discharge voltage was $4 \mathrm{kV}$, the wire length of the wire was $20 \mathrm{~mm}$, and the wire diameter was $1 \mathrm{~mm}$. According to the Equation (2):

$$
E=1 / 2 C_{g} U^{2}
$$

where, $E$ is the discharge energy, $C_{g}$ is the capacitance of the magnetic pulse generator with a value of $408 \mu \mathrm{F}, U$ is discharge voltage. The discharge energies corresponding to the discharge voltages of $4 \mathrm{kV}, 5 \mathrm{kV}$, and $6 \mathrm{kV}$ were $3.264 \mathrm{~kJ}, 5.1 \mathrm{~kJ}$, and $7.344 \mathrm{~kJ}$, respectively. The discharge energy of $3.264 \mathrm{~kJ}$ was released on a wire with a diameter of $1 \mathrm{~mm}$ and a length of $20 \mathrm{~mm}$. The shock wave generated was not sufficient to cause the inner pipe to deform significantly at the groove. The ultimate pull-out load of the joint was small. When the discharge voltage was $6 \mathrm{kV}$, the wire length was $15 \mathrm{~mm}$, and the wire diameter was $0.8 \mathrm{~mm}$, the ultimate pull-out load of the joint reached $16.95 \mathrm{kN}$.

Table 3. Ultimate pull-out load of joints.

\begin{tabular}{ccccccc}
\hline \multirow{2}{*}{ Samples } & \multicolumn{2}{c}{ Ultimate Pull-Out Load (kN) } & \multirow{2}{*}{ Samples } & & \multicolumn{2}{c}{ Ultimate Pull-Out Load (kN) } \\
\cline { 2 - 3 } & Actual & Predicted & & Actual & Predicted \\
\hline 1 & 11.09 & 11.47 & 11 & 12.55 & 12.33 \\
2 & 15.61 & 15.28 & 12 & 13.45 & 13.67 \\
3 & 13.76 & 12.22 & 13 & 13.45 & 13.67 \\
4 & 9.95 & 9.62 & 14 & 13.45 & 13.67 \\
5 & 9.52 & 10.40 & 15 & 14.71 & 15.09 \\
6 & 10.39 & 10.77 & 16 & 6.77 & 7.15 \\
7 & 13.45 & 13.67 & 17 & 16.95 & 16.62 \\
8 & 2.17 & 1.95 & 18 & & 16.87 & 16.65 \\
9 & 6.49 & 6.27 & 19 & & 13.45 & 13.67 \\
10 & 11.29 & 10.96 & 20 & & 13.45 & 13.67 \\
\hline
\end{tabular}

\subsection{Analysis of Variance Analysis and Mathematical Model}

The analysis of variance method was applied to evaluate the significance of the mathematical model. The purpose of analysis of variance was to explore whether the development of the model was significant. The influence of process parameters and their interactions on the mechanical properties of the joints was investigated.

The results of the analysis of variance are shown in Table 4. The Model F-value of 59.47 implied the model was significant. There was only less than $0.01 \%$ possibility that an F-value this large could occur due to noise. Considering the $95 \%$ reliability, the model with a probability value (the smallest significance level that may make the null hypothesis $\mathrm{H}_{0}$ negative) lower than 0.05 was considered significant [21]. In the analysis of variance, the linear terms $A, B$, and $C$ had a significant influence on the response. The quadratic term $A^{2}$ and $B^{2}$ did not have a significant influence on the response. The interaction term $A B$ and $B C$ did not have a significant influence on the response. In this study, $A, B, C, A C$, and $C^{2}$ were significant model terms, indicating that the influence of the factors on the ultimate pull-out load of the electrohydraulic expansion joints was not a simple linear relationship.

The coefficient of determination $\left(R^{2}\right)$ value was selected to describe the response surface of mechanical property (ultimate pull-out load). $R^{2}=0.9817$ suggested that the actual and predicted values were in good agreement based on the response surface method. The predicted values of response variable are presented in Table 3. The comparison between the actual and predicted values is shown in Figure 5. The data points were distributed near a straight line, indicating that the response surface could accurately predict the experimental results. 
Table 4. Analysis of variance in response surface method.

\begin{tabular}{cccccc}
\hline Source & Sum of Squares & Degree of Freedom & Mean Square & F-Value & $\begin{array}{c}p \text {-Value } \\
\text { Prob }>\text { F }\end{array}$ \\
\hline Model & 248.52 & 9 & 27.61 & 59.47 & $<0.0001$ \\
$A-A$ & 122.50 & 1 & 122.50 & 263.83 & $<0.0001$ \\
$B-B$ & 46.66 & 1 & 46.66 & 5.94 & $<0.0001$ \\
$C-C$ & 8.32 & 1 & 8.32 & 17.91 & 0.0017 \\
$A B$ & 0.00 & 1 & 0.00 & 0.00 & 1.00 \\
$A C$ & 22.85 & 1 & 22.85 & 49.21 & 0.0001 \\
$B C$ & 0.00 & 1 & 0.00 & 0.00 & 0.2111 \\
$A^{2}$ & 0.83 & 1 & 0.83 & 1.79 & 0.2111 \\
$B^{2}$ & 0.83 & 1 & 0.83 & 1.79 & 0.0027 \\
$C^{2}$ & 51.44 & 1 & 51.44 & 15.68 & \\
Residual & 4.64 & 10 & 0.46 & & \\
Lack of fit & 4.64 & 5 & 0.93 & & \\
Pure error & 0 & 5 & 0 & & \\
Cor total & 253.16 & 19 & & & \\
\hline
\end{tabular}

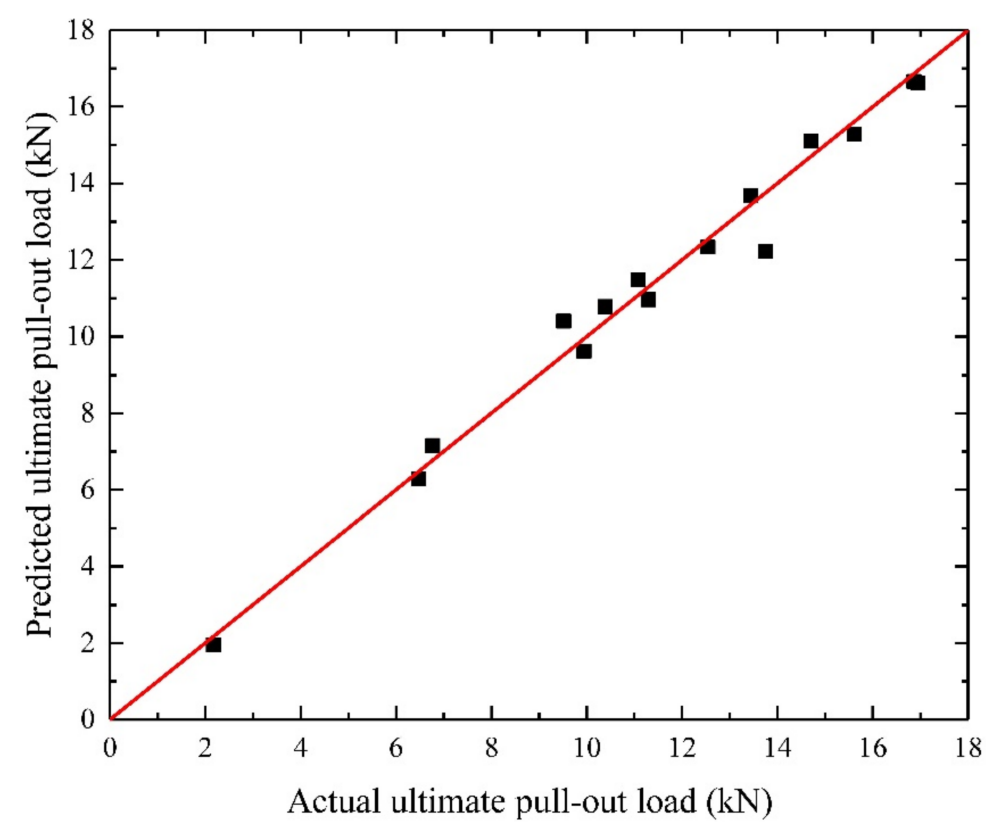

Figure 5. Comparison plot of prediction and actual values of the response.

In terms of actual factors, the multivariate quadratic nonlinear regression model for the ultimate pull-out load of the electrohydraulic expansion joints was:

$$
\begin{aligned}
y= & 2.23091 \times A+0.22691 \times B+47.55364 \times C-7.6079 \times 10^{-16} \times A \times B \\
& +8.45 \times A \times C-4.39344 \times 10^{-15} \times B \times C-0.54909 \times A^{2}-0.021964 \times B^{2} \\
& -58.97727 \times C^{2}-16.31691
\end{aligned}
$$

The multivariate quadratic nonlinear regression model derived from the coded factors was shown below:

$$
\begin{aligned}
y= & 3.50 \times A-2.16 \times B-0.91 \times C+1.69 \times A \times C \\
& -0.55 \times A^{2}-0.55 \times B^{2}-2.36 \times C^{2}+13.67
\end{aligned}
$$

where $y$ is ultimate pull-out load, $A$ is discharge voltage, $B$ is wire length, and $C$ is wire diameter. The equation based on actual factors and the equation represented by coding factors can be used to predict the response of each factor at a given level. The equation in terms of actual factors should not be used to determine the relative impact of each factor 
because the coefficients were scaled to accommodate the units of each factor. The equation in terms of coded factors could be useful for identifying the relative impact of the factors by comparing the factor coefficients.

\subsection{Effect of Single Factor on the Response}

In order to study the effect of the single factor on the response, the regression model was processed by dimensionality reduction method [27]. The single factor sub-regression model under specific conditions could be obtained by fixing the two factors in Equation (4) at the center level. As shown in Figure 6, firstly, by fixing the wire length at $15 \mathrm{~mm}$ and wire diameter at $0.8 \mathrm{~mm}$, the sub-regression model of discharge voltage for ultimate pull-out load could be obtained. Secondly, the sub-regression model of the wire length for ultimate pull-out load was obtained by fixing the discharge voltage at $5 \mathrm{kV}$ and wire diameter at $0.8 \mathrm{~mm}$. Finally, by fixing the wire length at $15 \mathrm{~mm}$ and discharge voltage at $5 \mathrm{kV}$, the sub-regression model of wire diameter for the ultimate pull-out load was obtained.

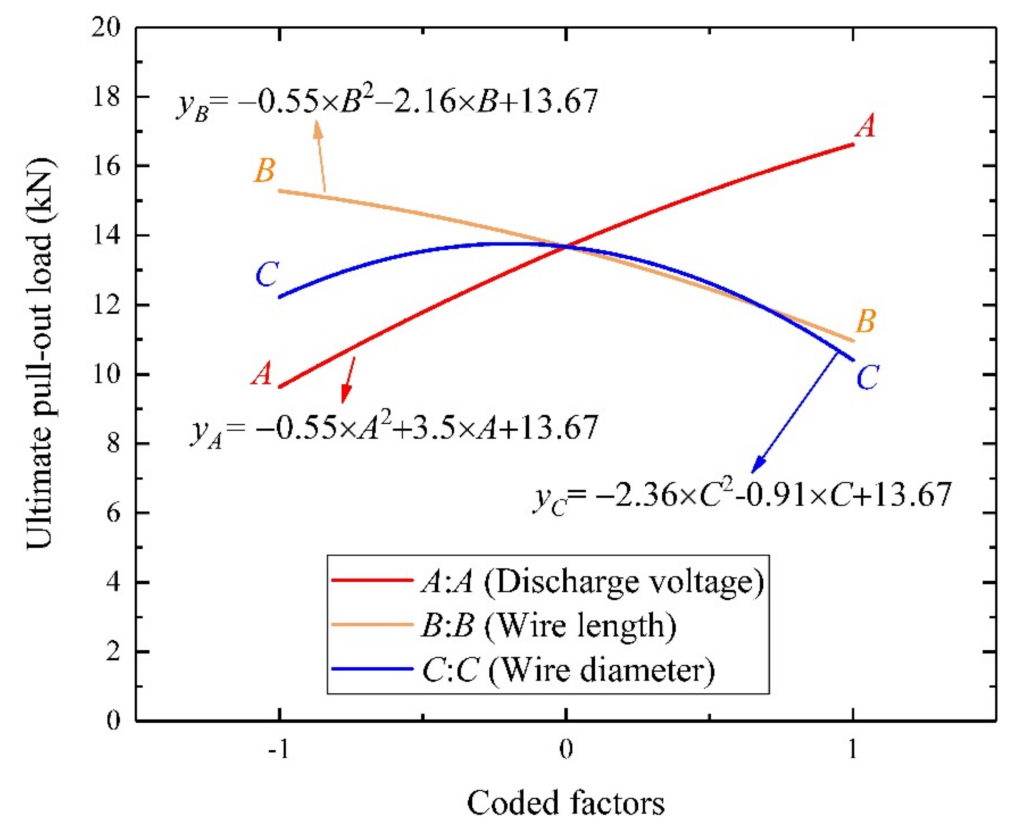

Figure 6. The single factor sub-regression model for ultimate pull-out load.

It can be seen from Figure 6 that the design variables $A, B$, and $C$ had a significant effect on the ultimate pull-out load. With the increase of discharge voltage $(A)$, the ultimate pull-out load showed a similar linear increasing trend. With the increase of the wire length (B), the ultimate pull-out load showed a similar linear decrease trend. The influence of the wire diameter $(C)$ on the ultimate pull-out load was in the form of a quadratic parabolic curve. With the increase of the wire diameter, the ultimate pull-out load first increased and then decreased.

\subsection{Interaction Effect of Parameters on Response}

In order to further explore the interaction of the two design variables, the threedimensional response surface map and contour map of the interaction of each experimental factor on the ultimate pull-out load were established, respectively. When analyzing the interaction of two parameters the response, the third parameter remained at the center level.

When the wire diameter was fixed at $0.8 \mathrm{~mm}$, the discharge voltage ranged from $4 \mathrm{kV}$ to $6 \mathrm{kV}$, and the wire length ranged from $10 \mathrm{~mm}$ to $20 \mathrm{~mm}$, Figure 7 shows the threedimensional surface map and contour map of the interaction effect of the discharge voltage and wire length on the ultimate pull-out load. 


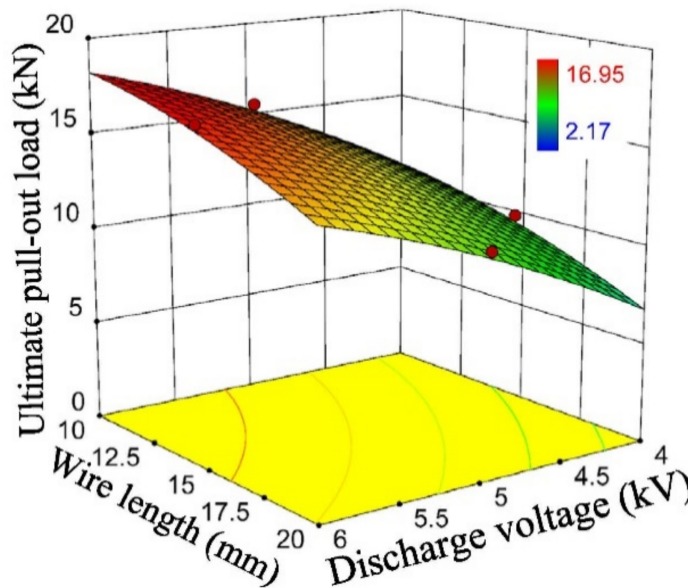

(a)

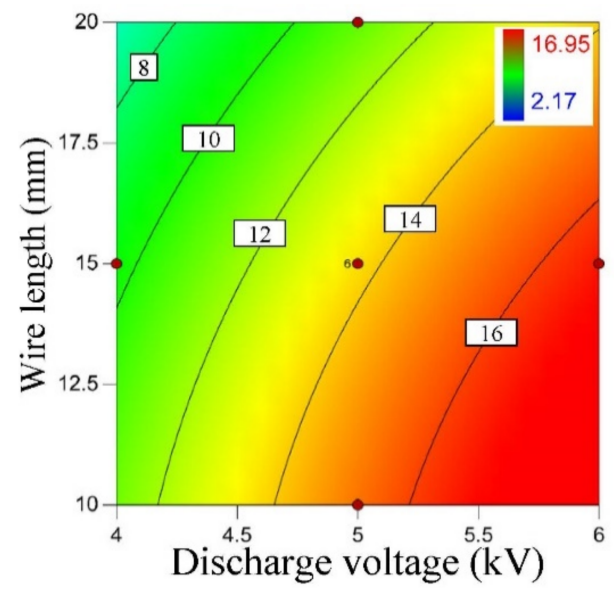

(b)

Figure 7. Three-dimensional surface map and contour map showing the interaction of discharge voltage and wire length: (a) three-dimensional surface map; (b) contour map.

As illustrated in Figure 7a, the ultimate pull-out load increased with the increase of the discharge voltage. As the discharge voltage increased, the discharge energy acting on the wire increased. The energy of the shock waves generated by the melt explosion increased. The inner and outer pipes were tightly connected at the groove. The ultimate pull-out load of the joints increased. The ultimate pull-out load decreased with the increase of the wire length. As the length increased, the wire might not have completely melted and exploded. The shock wave energy decreased, the inner pipe and outer pipe were not joined tightly enough. The ultimate pull-out load of the joints decreased.

As illustrated in Figure $7 \mathrm{~b}$, the increase of discharge voltage did not affect the effect of wire length on the ultimate pull-out load within the domain of the variables. The increase in wire length did not affect the effect of voltage on the ultimate pull-out load. These indicated that the interaction between discharge voltage and wire length was not significant, which was consistent with the results of the analysis of variance.

When the wire length was fixed at $15 \mathrm{~mm}$, the discharge voltage ranged from $4 \mathrm{kV}$ to $6 \mathrm{kV}$, and the wire diameter ranged from $0.6 \mathrm{~mm}$ to $1 \mathrm{~mm}$, Figure 8 shows the threedimensional surface map and contour map of the interaction effect of the discharge voltage and wire diameter on the ultimate pull-out load.

As illustrated in Figure 8a, the ultimate pull-out load increased with the increase of the discharge voltage. When the discharge voltage was lower than a certain value, the ultimate pull-out load decreased with the increase of the wire diameter. When the discharge voltage was greater than the certain value, the ultimate pull-out load increased first and then decreased with the increase of the wire diameter.

As illustrated in Figure 8b, the increase in the discharge voltage had an impact on the influence of the wire diameter on the ultimate pull-out load, which indicated that the interaction between discharge voltage and wire diameter was significant. This also indicated that the discharge voltage had a more significant influence than other factors. These results were consistent with the results of the analysis of variance. The possible reason was analyzed as follows. During the joining process, the energy stored in the capacitor was instantly released on the wire between the electrodes. Under the action of Joule heat, the wire underwent a sharp phase change. It experienced solid state, liquid state, gas state, and plasma state successively, and finally developed into a plasma channel. It was accompanied by physical phenomena such as light radiation and shock waves [28,29]. The vaporization of the wire was crucial for the generation of the shock wave. The initial stored energy should be higher than the complete vaporization energy of the wire [30]. The 
study found that there was an area of wire diameter in which most of the initially stored energy can be deposited in the wire. The reason was that the average current density of the thick wire was too low, the initial stored energy was not effectively transferred to the wire. While the diameter of the wire was small, it exploded too fast, leaving a lot of energy on the pulse forming line $[31,32]$.

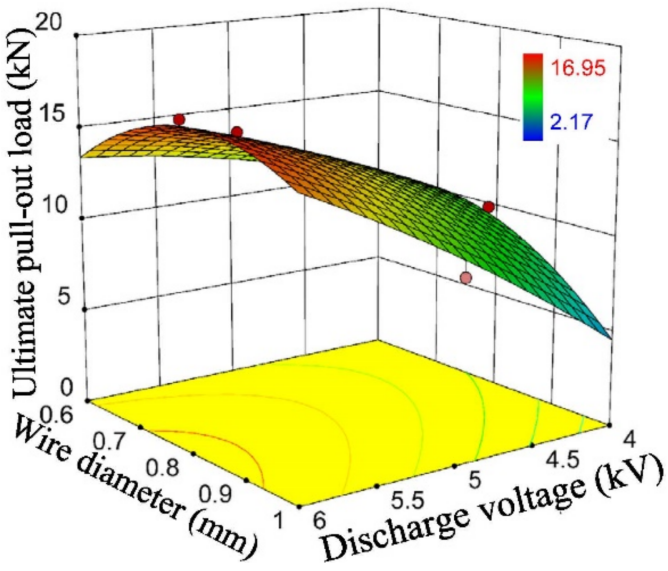

(a)

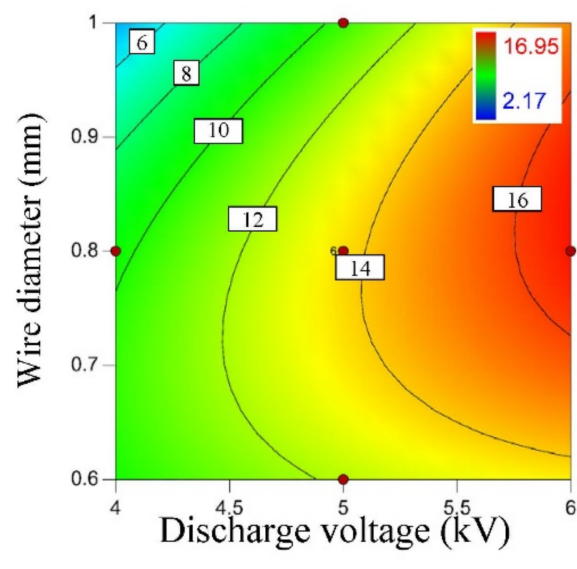

(b)

Figure 8. Three-dimensional surface map and contour map showing the interaction of discharge voltage and wire diameter: (a) three-dimensional surface map; (b) contour map.

When the discharge voltage was fixed at $5 \mathrm{kV}$, the wire length ranged from $10 \mathrm{~mm}$ to $20 \mathrm{~mm}$, and the wire diameter ranged from $0.6 \mathrm{~mm}$ to $1 \mathrm{~mm}$. Figure 9 shows the threedimensional surface map and contour map of the interaction effect of wire length and wire diameter on the ultimate pull-out load.

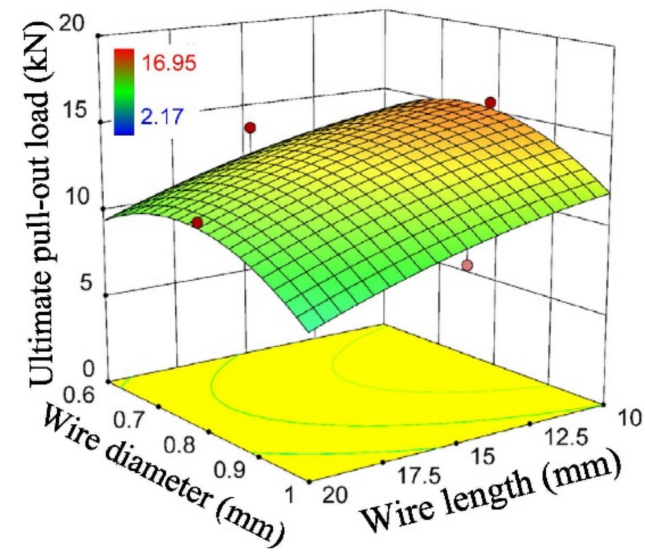

(a)

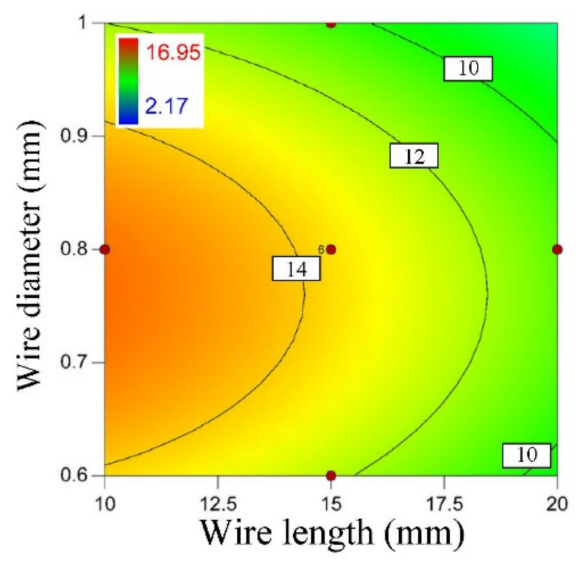

(b)

Figure 9. Three-dimensional surface map and contour map showing the interaction of wire length and wire diameter: (a) three-dimensional surface map; (b) contour map.

As illustrated in Figure 9a, the ultimate pull-out load decreased with the increase of the wire length. The ultimate pull-out load increased first and then decreased with the increase of the wire diameter. As illustrated in Figure 9b, the increase of the wire length did not affect the effect of wire diameter on the ultimate pull-out load within the domain of the variables. The increase in wire diameter did not affect the effect of wire length on the ultimate pull-out load. This indicated that the interaction between wire length and wire diameter was not significant, which was consistent with the results of the analysis of variance. The possible reason was analyzed as follows. As the length of the metal wire 
increased, the uniformity of the phase change of the metal wire decreased. Factors such as phase change and thermal stress would cause the phase explosion or breakdown in some areas of the wire to form plasma in advance [33].

\subsection{Parameter Optimization and Validation}

By analyzing the quadratic regression equation, it was found that when the discharge voltage was $6 \mathrm{kV}$, wire length was $10 \mathrm{~mm}$ and the wire diameter was $0.833 \mathrm{~mm}$, the ultimate pull-out load reached its peak, which was $18.296 \mathrm{kN}$. To verify the model, experiments were performed on the optimal combination of parameters. As shown in Figure 10, when the discharge voltage was $6 \mathrm{kV}$, wire length was $10 \mathrm{~mm}$ and the wire diameter was $0.8 \mathrm{~mm}$, the average value of the ultimate pull-out load was $18.57 \mathrm{kN}$ in the three groups of experiments. The relative error between the experimental value and the predicted value was $1.5 \%$. Therefore, the model could be used to predict the optimal process parameters.

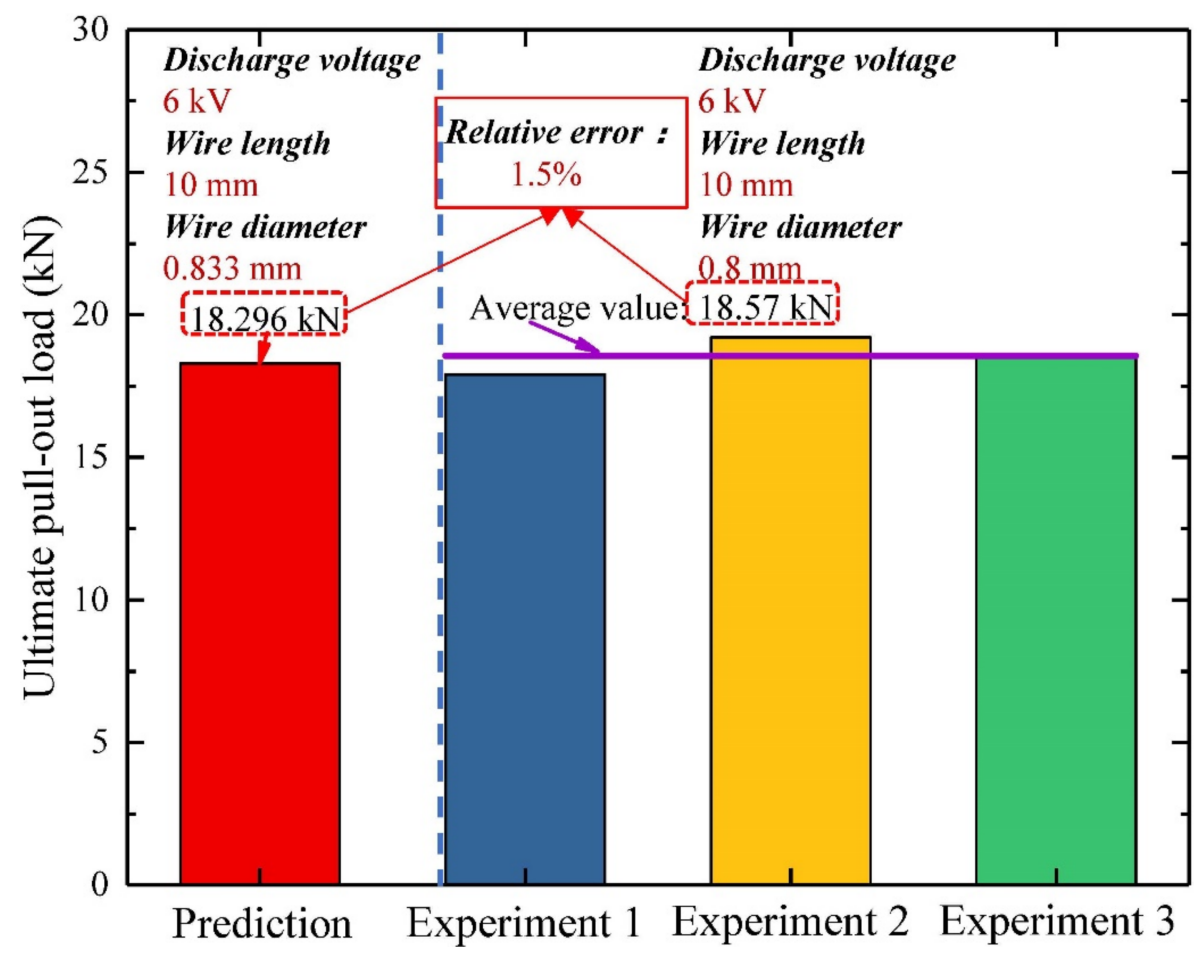

Figure 10. Predicted and experimental values based on optimized parameters.

\section{Conclusions}

In this paper, multiple experiments of electrohydraulic expansion joining based on the response surface methodology have been conducted. The main conclusions were drawn as follows:

(1) The results of the multivariate quadratic nonlinear regression model of the ultimate pull-out load of electrohydraulic expansion joints were in good agreement with the experimental results, which indicated that the model could accurately predict the ultimate pull-out load.

(2) The discharge voltage, wire length, and wire diameter had a significant effect on the ultimate pull-out load. The discharge voltage had the most significant effect. The interaction between the discharge voltage and the wire diameter had a significant effect on the ultimate pull-out load.

(3) The optimal parameter combination was obtained when the discharge voltage was $6 \mathrm{kV}$, wire length was $10 \mathrm{~mm}$, and the wire diameter was $0.833 \mathrm{~mm}$, the ultimate pullout load reached its peak, which was $18.296 \mathrm{kN}$. This research created an experimental database for the practical application and further promotion of electrohydraulic 
expansion joining process. It also provided guidance for the choice of the process parameters in real applications.

Author Contributions: Conceptualization, D.C.; methodology, D.C. and J.L.; software, C.J. and J.L.; validation, C.J. and J.L.; formal analysis, G.L.; investigation, G.L.; resources, J.C.; data curation, C.J.; writing-original draft preparation, D.C.; writing-review and editing, J.C.; visualization, D.C.; supervision, J.C.; project administration, J.C.; funding acquisition, J.C. All authors have read and agreed to the published version of the manuscript.

Funding: This project is supported by National Natural Science Foundation of China (No. 51975202) and the Natural Science Foundation of Hunan Province (2019JJ30005).

Institutional Review Board Statement: Not applicable.

Informed Consent Statement: Not applicable.

Data Availability Statement: The raw/processed data and material required to reproduce these findings cannot be shared at this time due to technical or time limitations.

Conflicts of Interest: The authors declare no conflict of interest.

\section{References}

1. Liang, Q.; Zhang, T.; Zhu, C.; Bi, Y. Effect of riveting angle and direction on fatigue performance of riveted lap joints. Coatings 2021, 11, 236. [CrossRef]

2. Jiang, H.; Zeng, C.C.; Li, G.Y.; Cui, J.J. Effect of locking mode on mechanical properties and failure behavior of CFRP/Al electromagnetic riveted joint. Compos. Struct. 2021, 257, 113162. [CrossRef]

3. Zhu, C.C.; Sun, L.Q.; Gao, W.L.; Li, G.Y.; Cui, J.J. The effect of temperature on microstructure and mechanical properties of $\mathrm{Al} / \mathrm{Mg}$ lap joints manufactured by magnetic pulse welding. J. Mater. Res. Technol.-JMRT 2019, 8, 3270-3280. [CrossRef]

4. Weddeling, C.; Woodward, S.T.; Marre, M.; Nellesen, J.; Psyk, V.; Tekkaya, A.E.; Tillmann, W. Influence of groove characteristics on strength of form-fit joints. J. Mater. Process. Technol. 2011, 211, 925-935. [CrossRef]

5. Duan, L.M.; Jiang, H.; Zhang, X.; Li, G.Y.; Cui, J.J. Experimental investigations of electromagnetic punching process in CFRP laminate. Mater. Manuf. Process. 2021, 36, 223-234. [CrossRef]

6. Wang, S.L.; Zhou, B.B.; Zhang, X.; Sun, T.; Li, G.Y.; Cui, J.J. Mechanical properties and interfacial microstructures of magnetic pulse welding joints with aluminum to zinc-coated steel. Mater. Sci. Eng. A 2020, 788, 139425. [CrossRef]

7. Marre, M.; Brosius, A.; Tekkaya, A.E. Joining by compression and expansion of (none-) reinforced profiles. Adv. Mater. Res. Flex. Manuf. Lightweight Fram. Struct. Phase II Integr. 2008, 43, 57-68. [CrossRef]

8. Barnes, T.A.; Pashby, I.R. Joining techniques for aluminum spaceframes used in automobiles, Part I—Solid and liquid phase welding. Mater. Manuf. Process. 1998, 99, 62-71. [CrossRef]

9. Mori, K.; Bay, N.; Fratini, L.; Fabrizio, M.; Tekkaya, A.E. Joining by plastic deformation. CIRP Ann.-Manuf. Technol. 2013, 62, 673-694. [CrossRef]

10. Henriksen, J.; Nordhagen, H.O.; Hoang, H.N. Hansen, M.R.; Thrane, F.C. Numerical and experimental verification of new method for connecting pipe to flange by cold forming. J. Mater. Process. Technol. 2015, 220, 215-223. [CrossRef]

11. Marre, M.; Rautenberg, J.; Tekkaya, A.E.; Zabel, A.; Biermann, D.; Wojciechowski, J.; Przybylski, W. An experimental study on the groove design for joints produced by hydraulic expansion considering axial or torque load. Mater. Manuf. Process. 2012, 27, 545-555. [CrossRef]

12. Shirgaokar, M.; Cho, H.; Ngaile, G.; Altan, T.; Yu, J.H.; Balconi, J.; Rentfrow, R.; Worrell, W.J. Optimization of mechanical crimping to assemble tubular components. J. Mater. Process. Technol. 2004, 146, 35-43. [CrossRef]

13. Cho, J.R.; Song, J.I. Swaging process of power steering hose: Its finite element analysis considering the stress relaxation. J. Mater. Process. Technol. 2007, 187-188, 497-501. [CrossRef]

14. Shirgaokar, M.; Ngaile, G.; Altan, T.; Yu, J.H.; Balconi, J.; Rentfrow, R.; Worrell, W.J. Hydraulic crimping: Application to the assembly of tubular components. J. Mater. Process. Technol. 2004, 146, 44-51. [CrossRef]

15. Li, G.Y.; Deng, H.K.; Mao, Y.F.; Zhang, X.; Cui, J.J. Study on AA5182 aluminum sheet formability using combined quasi-staticdynamic tensile processes. J. Mater. Process. Technol. 2018, 255, 373-386. [CrossRef]

16. Psyk, V.; Risch, D.; Kinsey, B.L.; Tekkaya, A.E.; Kleiner, M. Electromagnetic forming-A review. J. Mater. Process. Technol. 2011, 211, 787-829. [CrossRef]

17. Weddeling, C.; Demir, O.K.; Haupt, P.; Tekkaya, A.E. Analytical methodology for the process design of electromagnetic crimping. J. Mater. Process. Technol. 2015, 222, 163-180. [CrossRef]

18. Cai, D.; Liang, J.; Ou, H.; Li, G.Y.; Cui, J.J. Mechanical properties and joining mechanism of electrohydraulic expansion joints for 6063 aluminum alloy/304 stainless steel thin-walled pipes. Thin-Walled Struct. 2021, 161, 107427. [CrossRef]

19. Golovashchenko, S.F.; Gillard, A.J.; Mamutov, A.V.; Bonnen, J.F.; Tang, Z.J. Electrohydraulic trimming of advanced and ultra high strength steels. J. Mater. Process. Technol. 2014, 214, 1027-1043. [CrossRef] 
20. Liu, X.; Gu, W.B.; Liu, J.Q.; Xu, J.L.; Hu, Y.H.; Hang, Y.M. Dynamic response of cylindrical explosion containment vessels subjected to internal blast loading. Int. J. Impact Eng. 2019, 135, 103389. [CrossRef]

21. Zohoor, M.; Mousavi, S.M. Evaluation and optimization of effective parameters in electrohydraulic forming process. J. Braz. Soc. Mech. Sci. Eng. 2018, 40,1-17. [CrossRef]

22. Jiang, H.; Liao, Y.X.; Gao, S.; Li, G.Y.; Cui, J.J. Comparative study on joining quality of electromagnetic driven self-piecing riveting, adhesive and hybrid joints for Al/steel structure. Thin-Walled Struct. 2021, 164, 107903. [CrossRef]

23. Cui, J.J.; Li, Y.; Liu, Q.X.X.; Zhang, X.; Xu, Z.D.; Li, G.Y. Joining of tubular carbon fiber-reinforced plastic/aluminum by magnetic pulse welding. J. Mater. Process. Technol. 2019, 264, 273-282. [CrossRef]

24. Zou, S.Z.; Wang, H.; Wang, X.J.; Zhou, S.; Li, X.; Feng, Y.Z. Application of experimental design techniques in the optimization of the ultrasonic pretreatment time and enhancement of methane production in anaerobic co-digestion. Appl. Energy 2016, 179, 191-202. [CrossRef]

25. Varesio, E.; Gauvrit, J.Y.; Longeray, R.; Lantéri, P.; Veuthey, J.L. Central composite design in the chiral analysis of amphetamines by capillary electrophoresis. Electrophoresis 1997, 18, 931-937. [CrossRef] [PubMed]

26. Bas, D.; Boyac1, I.H. Modeling and optimization I: Usability of response surface methodology. J. Food Eng. 2007, 78, 836-845.

27. Auricchio, F.; Balduzzi, G.; Khoshgoftar, M.J.; Rahimi, G.; Sacco, E. Enhanced modeling approach for multilayer anisotropic plates based on dimension reduction method and Hellinger-Reissner principle. Compos. Struct. 2014, 118, 622-633. [CrossRef]

28. Yao, W.B.; Zhou, H.B.; Han, R.Y.; Zhang, Y.M.; Zhao, Z.; Xu, Q.F.; Qiu, A.C. An empirical approach for parameters estimation of underwater electrical wire explosion. Phys. Plasmas 2019, 26, 093502. [CrossRef]

29. Virozub, A.; Gurovich, V.T.; Yanuka, D.; Antonov, O.; Krasik, Y.E. Addressing optimal underwater electrical explosion of a wire. Phys. Plasmas 2016, 23, 092708. [CrossRef]

30. Li, L.X.; Qian, D.; Zou, X.B.; Wang, X.X. Effect of deposition energy on underwater electrical wire explosion. IEEE Trans. Plasma Sci. 2018, 46, 3444-3449. [CrossRef]

31. Grinenko, A.; Krasik, Y.E.; Efimov, S.; Fedotov, A.; Gurovich, V.T.; Oreshkin, V.I. Nanosecond time scale, high power electrical wire explosion in water. Phys. Plasmas 2006, 13, 042701. [CrossRef]

32. Zhou, Q.; Zhang, Q.G.; Zhang, J.; Zhao, J.P.; Pang, L.; Ren, B.Z. Effect of circuit parameters and wire properties on exploding a copper wire in water. IEEE Trans. Plasma Sci. 2011, 39, 1606-1612. [CrossRef]

33. Suhara, T.; Fukuda, S. Experimental determination of optimum condition for wire explosion in water and PMMA. Proc. SPIE 1979, 189, 321-326. 